\title{
Prevalence of vitamin D deficiency in pregnant women and their babies in Bhaktapur, Nepal
}

\author{
Dhruba Shrestha ${ }^{1 *}$ DD, Saraswati Budhathoki', Sabi Pokhrel', Ashok Kumar Sah', Raj Kumar Shrestha', \\ Ganendra Bhakta Raya ${ }^{1}$, Reena Shrestha ${ }^{1}$, Rasila Pasakhala' ${ }^{1}$ Christopher Smith ${ }^{2}$ and Bhim Gopal Dhoubhadel ${ }^{2}$
}

\begin{abstract}
Background: Vitamin D deficiency has been observed worldwide in pregnant women and their newborns. Maternal vitamin D deficiency can lead to deficiency in their newborn baby and has been linked with various complications during pregnancy and delivery. There is risk of premature delivery and it is associated with high neonatal mortality.

Methods: Seventy-nine pregnant women who were admitted to the Siddhi Memorial Hospital for delivery and their newborn babies were enrolled in the study. Maternal blood samples were taken before delivery while umbilical cord blood samples of their babies were taken after delivery. Serum vitamin D level and calcium level were assessed by fluorescence immunoassay using Ichromax vitamin D kit and endpoint method, respectively in the Siddhi Memorial Hospital laboratory.

Results: Mean +/- SD serum vitamin D and calcium levels in pregnant mother before delivery were 14.6 $+/-8.5 \mathrm{ng} / \mathrm{ml}$ and $8.0+/-0.5 \mathrm{mg} / \mathrm{dl}$, respectively, and in the cord blood were $25.7+/-11.2 \mathrm{ng} / \mathrm{ml}$ and 8.6 $+/-0.9 \mathrm{mg} / \mathrm{dl}$, respectively. Eighty-one percent of the mothers and $35.8 \%$ of their babies were found to have vitamin D deficiency. Although $97.5 \%$ of the pregnant women were taking calcium supplementation, serum calcium was found lower than the normal reference value in $67 \%$ of the pregnant women and $64.2 \%$ of their babies. There were a linear relationship between the maternal and baby's serum vitamin $D(P<0.001)$ and calcium $(P<0.001)$ levels.
\end{abstract}

Conclusion: There is high prevalence of vitamin $D$ and calcium deficiency in pregnant mothers and newborn babies in Bhaktapur, Nepal. Pregnant women need to be supplemented with adequate amounts of these nutrients.

Keywords: Vitamin D, Calcium, Pregnancy, Newborn, Nutrition, Deficiency, Supplementation, Nepal, Asia

\section{Background}

Vitamin D deficiency is observed worldwide in pregnant women and their neonates [1-5]. Maternal vitamin D deficiency is associated with various problems in their babies such as preterm delivery, low birth weight, neonatal hypocalcemia etc. that can be associated with neonatal deaths [6].

Vitamin D deficiency can be present in people who have a vegetarian diet, who are not adequately exposed to sunlight, or consume a low amount of dairy products.

\footnotetext{
* Correspondence: drdhrubashr@hotmail.com

${ }^{1}$ Department of Paediatrics, Siddhi Memorial Hospital, Bhaktapur, Nepal Full list of author information is available at the end of the article
}

Vitamin D is transferred to the fetus from mother. Vitamin D deficiency in mother can lead to deficiency in the newborn baby. Vitamin D and calcium requirements during pregnancy are higher than the normal recommended dose. But the exact dose of calcium and vitamin D supplementation is still debatable [7]. Human milk contains $15-50 \mathrm{IU} / \mathrm{L}$ of vitamin $\mathrm{D}$ which is inadequate to fulfill the daily requirement of the growing baby [8]. Hence exclusively breastfed babies might be at risk of vitamin D deficiency. The American Academy of Pediatrics (AAP) has recommended to supplement all exclusively breast fed neonates with $200 \mathrm{IU} /$ day of vitamin D3 to prevent adverse events due to vitamin D deficiency [9].

(c) The Author(s). 2019 Open Access This article is distributed under the terms of the Creative Commons Attribution 4.0 International License (http://creativecommons.org/licenses/by/4.0/), which permits unrestricted use, distribution, and 
Studies conducted in south-east Asian region have shown people living in this area are prone to vitamin D deficiency $[10,11]$, and its prevalence in some areas is more than $80 \%$ [12-14]. To our knowledge, vitamin D status in pregnant women and their newborn babies in Nepal has not been studied and the country is in high prone area. In this study we examine the prevalence of vitamin $\mathrm{D}$ and calcium deficiency among pregnant women and their babies in Bhaktapur, Nepal.

\section{Methods}

\section{Study design and setting}

This is a cross-sectional study conducted from November 2017 to April 2018 in Siddhi Memorial Hospital, located in Bhaktapur, Nepal; a local non-governmental maternal and children hospital that provides specialized services to pregnant mothers and children in the district.

\section{Enrollment, sample collection and testing for vitamin D and calcium}

All pregnant women who were admitted to the hospital during the study period were approached for the study. Women who denied to participate in the study or had some medical complications such as pregnancy induced hypertension; gestational diabetes mellitus and hypothyroidism were excluded from the enrollment in the study. After counseling and informed consent the eligible women were enrolled in the study. Five $\mathrm{ml}$ of venous blood sample was taken for the laboratory test of vitamin $\mathrm{D}$ and calcium.

After delivery of a baby, cord was clamped and cut. Five $\mathrm{ml}$ of cord blood was obtained from the segment attached to the placenta before the placenta was delivered. Both the blood samples of mother and baby were processed and serum was collected in Siddhi Memorial Hospital laboratory. The serum was then tested for serum vitamin D level and calcium level. 25-Hydroxyvitamin D (25(OH)D2/D3) was analyzed by fluorescence immunoassay using Ichromax Vitamin D kit (Boditech Med Inc., Korea). The assay had the coefficient of variation (CV) $<10 \%$ and comparability 0.954 for the detection of vitamin D in serum. Total serum calcium level was analyzed by using o-Cresolphthalein Complexone (o-CPC) method (Accurex Biomedical Pvt. Ltd., India).

\section{Data collection and statistical analysis}

Demographic and clinical data were first collected in a standardized questionnaire in a paper form which were later transferred into Epi Info 7 software (Version no. 7.2.1, CDC, Atlanta, USA). Statistical analyses were performed using STATA 14 (StataCorp, Texas, USA). Continuous variables were presented as means and the standard deviation (SD), and categorical variables as proportions (\%). The serum level of vitamin D and calcium were categorized as shown in Table 1. Linear regression was performed in order to look for the association between maternal and cord blood vitamin D and calcium level. Multivariate linear regression was performed to adjust possible confounding factors: sex, gestational age, and birth weight. $P$ value of less than 0.05 was taken as significant.

\section{Ethical consideration}

Informed written consent was taken from the admitted mother before enrolling in the study and testing for blood samples for vitamin D and calcium. The research was approved by Nepal Health Research Council (NHRC), Kathmandu (Registration number: 329/2017).

\section{Results}

There were 106 pregnant women admitted to the hospital for delivery during in the study period out of which 79 pregnant women were included in the study; two had twin babies, so the total numbers of babies in the study were 81 (Fig. 1). The mean age of mothers was 26.7 years with a minimum of 18 years and the maximum of 38 years. General characteristics of the mothers are shown in Table 2. 97.5\% (77/79) of the mothers took iron supplementation during the pregnancy, 69.6\% (55/79) took folic acid, and 97.5\% (77/79) took calcium supplementation. General characteristics of the babies are shown in Table 3. One fifth (19.7\%) of the babies were low birth weight $(<2.5 \mathrm{~kg})$ and $7.6 \%(6 / 81)$ were preterm.

The prevalence of vitamin D deficiency $[<20 \mathrm{ng} / \mathrm{ml}]$ and insufficient vitamin D level [20-30 ng/ml] among pregnant women at the time of delivery were $81 \%(64 /$ 79 ) and $11.39 \%$ (9/79), respectively. Similarly, 67\% (53/ 79) of the pregnant mothers had lower serum calcium level than the desired value [8.4-10.2 mg/dl]. 35.8\% (29/ $81)$ and $64.2 \%(52 / 81)$ of the babies were found to have vitamin D deficiency $[<20 \mathrm{ng} / \mathrm{ml}]$ and calcium deficiency [ $<9 \mathrm{mg} / \mathrm{dl}]$ in their cord blood, respectively (Table 4).

Serum vitamin D levels in mothers and babies were plotted in a scatter plot (Fig. 2). The association of the

Table 1 Reference range of vitamin D and calcium

\begin{tabular}{ll}
\hline Status & $\mathrm{ng} / \mathrm{ml}(\mathrm{nmol} / \mathrm{L})$ \\
Vitamin D [29] & \\
$\quad$ Deficiency & $<20(<50)$ \\
Insufficiency & $20-29(50-75)$ \\
Sufficiency & $30-100(75-250)$ \\
Potential toxicity & $>100(>250)$ \\
& $\mathrm{mg} / \mathrm{dl}(\mathrm{mmol} / \mathrm{L})$ \\
Total serum calcium & \\
Cord blood & $9.0-11.5(2.2-2.8)$ \\
Adult & $8.4-10.2(2.1-2.5)$ \\
\hline
\end{tabular}




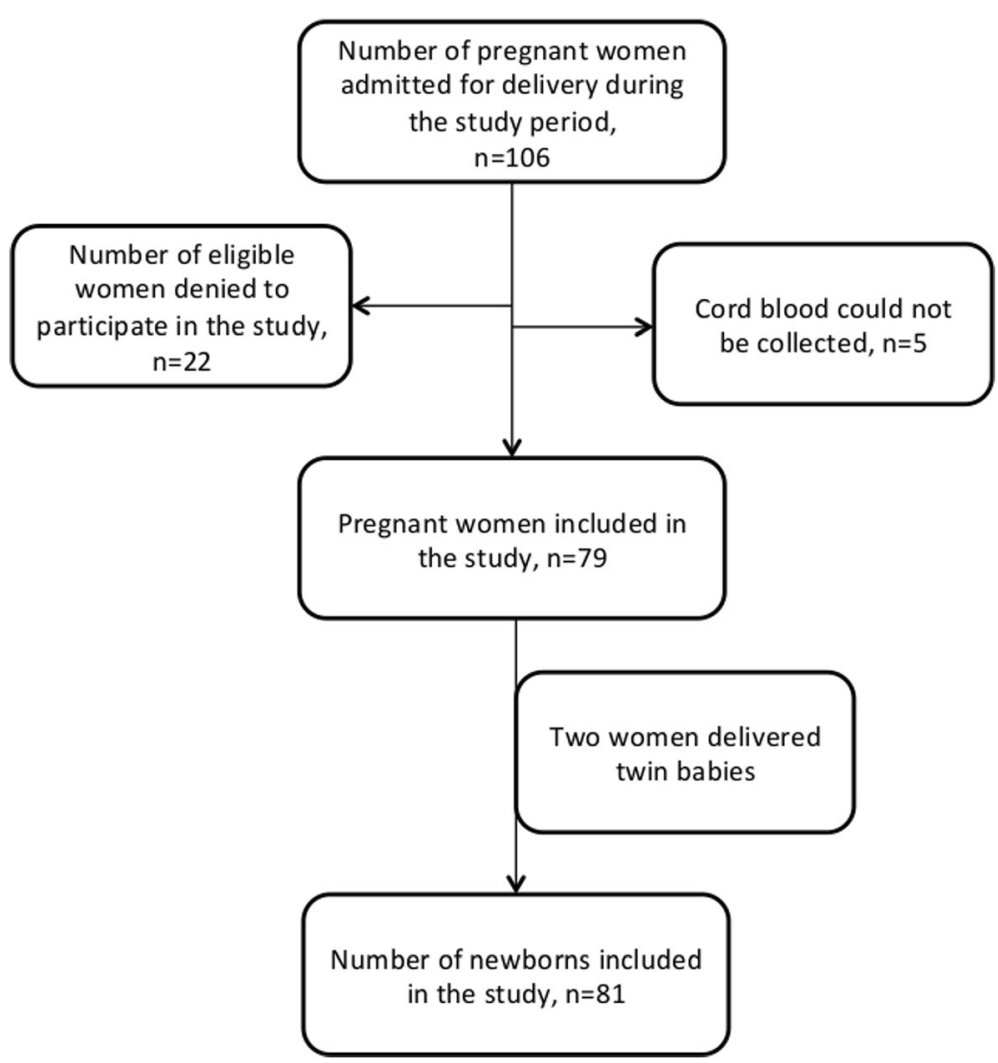

Fig. 1 Flow chart of enrollment of pregnant women for the study

vitamin $\mathrm{D}$ levels in mothers with babies was explored by using the linear regression model; the coefficient of regression was 1.05 (95\% CI $0.89-1.21 ; P<0.001)$ and 1.04 (95\% CI $0.88-1.02 ; P<0.001)$ when adjusted with sex, birth weight and gestational age. Among the pregnant women and babies with vitamin $\mathrm{D}$ level $<30 \mathrm{ng} / \mathrm{ml}$, the coefficient of regression was 0.84 (95\% CI $0.52-1.17$; $P<$ $0.001)$ and 0.83 (95\% CI $0.51-1.15 ; P<0.001)$ when adjusted with the covariates. Similarly, the relationship between serum calcium level in mothers and in babies was explored. The coefficient of regression was 0.52 (95\% CI 0.29-0.76; $P<0.001$ ), and 0.53 (95\% CI 0.29-0.76) when adjusted for the covariates. Among the pregnant mothers with serum calcium $<8.4 \mathrm{mg} / \mathrm{dl}$ and babies with cord blood level $<9.0 \mathrm{mg} / \mathrm{dl}$, the coefficient was 0.54 (95\% CI $0.22-0.86 ; P=0.001)$ and 0.53 (95\% CI $0.21-$ $0.85 ; P=0.002)$ when adjusted with the covariates.

\section{Discussion}

This study showed a high prevalence of vitamin D deficiency and a high prevalence of lower than desired level of calcium among pregnant women and their newborn babies in Bhaktapur, Nepal. The levels of the micronutrients in mothers had a linear relationship with those of newborn babies. To our knowledge, this is the first study specifically looking into the relationship of vitamin D level in pregnant women and their newborn babies in Nepal. Few studies showed high a prevalence of vitamin $\mathrm{D}$ deficiency in general population $[15,16]$. In a study conducted in Nepal vitamin D deficiency $(<20 \mathrm{ng} / \mathrm{ml})$ was observed in $81 \%$ of the pregnant women and serum calcium level was less than the desired value in $67 \%$ of the mothers [17].

Vitamin D deficiency is observed worldwide in all age groups [13-18]. Deficiency during pregnancy and childbirth poses more threat to health than in other periods of life $[4-6,19,20]$. This can be prevented by nutrient supplementation. South Asia is considered to be high-risk area for vitamin D deficiency because of its geographical location and dark skin color of the people $[10,13]$. A study done in a rural part of North India showed vitamin D deficiency $(<20 \mathrm{ng} / \mathrm{ml})$ in $88.6 \%$ of adolescent girls and $74 \%$ of pregnant women [21]; similarly another study in the same region found $85 \%$ of pregnant women and $95 \%$ of their newborn babies had vitamin $\mathrm{D}$ deficiency with a positive correlation between maternal and cord blood vitamin D level [12]. Many studies have shown a positive correlation between maternal and babies' vitamin D levels as vitamin D is transferred from mother to fetus via placenta [20, 22-24].

Pregnant women in Nepal are regularly supplemented with calcium and vitamin D3 tablets containing $500 \mathrm{mg}$ 
Table 2 General characteristics of pregnant women admitted for delivery to Siddhi Memorial Hospital

\begin{tabular}{|c|c|}
\hline Characteristics & Frequency, $n=79(\%)$ \\
\hline Age [mean (SD)], years & $26.7(4.7)$ \\
\hline Height [mean (SD)], cm & $151.9(10.7)$ \\
\hline Weight [mean (SD)], kg & $65.2(9.1)$ \\
\hline Duration of marriage [mean (SD)], years & $4.5(3.9)$ \\
\hline \multicolumn{2}{|l|}{ Education } \\
\hline Masters & $7(8.9)$ \\
\hline Bachelor & $21(26.6)$ \\
\hline Intermediate & $23(29.1)$ \\
\hline SLC & $5(6.3)$ \\
\hline School & $23(29.1)$ \\
\hline \multicolumn{2}{|l|}{ Occupation } \\
\hline Housewife & $47(59.5)$ \\
\hline Service Holder & $23(29.1)$ \\
\hline Business & $7(8.8)$ \\
\hline Farmer & $1(1.3)$ \\
\hline Student & $1(1.3)$ \\
\hline \multicolumn{2}{|l|}{ Dietary habit } \\
\hline Vegetarian & $3(3.8)$ \\
\hline Non -vegetarian & $76(96.2)$ \\
\hline \multicolumn{2}{|l|}{ Blood group } \\
\hline$A+$ & $32(40.5)$ \\
\hline $0+$ & $21(26.6)$ \\
\hline $\mathrm{B}+$ & $16(20.2)$ \\
\hline$A B+$ & $8(10.1)$ \\
\hline A- & $1(1.3)$ \\
\hline B- & $1(1.3)$ \\
\hline \multicolumn{2}{|l|}{ No. of previous deliveries } \\
\hline 0 & $46(58.2)$ \\
\hline 1 & $27(34.2)$ \\
\hline 2 & $4(5.1)$ \\
\hline 3 & $2(2.5)$ \\
\hline Gestational age [mean (SD)], weeks & $38.4(1.7)$ \\
\hline \multicolumn{2}{|l|}{ Type of delivery } \\
\hline Vaginal delivery & $35(44.3)$ \\
\hline Emergency caesarian section & $32(40.51)$ \\
\hline Elective caesarian section & $12(15.2)$ \\
\hline
\end{tabular}

of elemental calcium and 250 IU of vitamin D3 (cholecalciferol) after first trimester of pregnancy. The WHO has recommended 1 to $2 \mathrm{~g}$ of elemental calcium during pregnancy and child birth, but not a regular vitamin $\mathrm{D}$ supplementation during normal pregnancy [24-27]. However, the Royal College of Obstetricians and Gynecologists (RCOG) of the United Kingdom and the American College of Obstetricians and Gynecologists
Table 3 General characteristics of newborn babies

\begin{tabular}{ll}
\hline Characteristics & $n=81(\%)$ \\
\hline Sex & $44(54.3)$ \\
Male & $37(45.7)$ \\
$\quad$ Female & \\
Birth weight, kg & $16(19.7)$ \\
$<2.5$ & $65(80.2)$ \\
$2.5-4$ & $48.5(3.4)$ \\
Birth length [mean (SD)], cm & $33.7(1.7)$ \\
Head circumference [mean (SD)], cm & \\
Gestation & $6(7.6)$ \\
Preterm (<37 weeks) & $73(92.4)$ \\
Term (37 to 42 weeks) & \\
Outcome & $9(11.1)$ \\
Admitted for observation & $72(88.9)$ \\
$\quad$ Normal &
\end{tabular}

(ACOG) has recommended at least $400 \mathrm{IU}$ of vitamin D3 supplementation during pregnancy $[2,28]$. As the region is prone to vitamin $\mathrm{D}$ deficiency and studies have shown high prevalence of deficiency in the region, it should be considered to follow the recommendation of these Royal Colleges to provide at least $400 \mathrm{IU}$ of vitamin D3 as a regular supplementation to Nepalese pregnant women.

Serum calcium is an important marker of vitamin D activity. An adequate amount of vitamin $D$ is required for maintenance of calcium homeostasis $[8,28]$. There is a risk of calcium deficiency when there is vitamin $\mathrm{D}$ deficiency. Positive correlation between maternal serum vitamin $\mathrm{D}$ and calcium with that of cord blood vitamin $\mathrm{D}$ and calcium level has been documented [1, 4, 12]. Determining vitamin $\mathrm{D}$ and calcium level in pregnant mothers can help us to predict their levels in newborns. In our study, the linear relationship is stronger for the

Table 4 Summary of serum vitamin D and calcium levels in mothers and newborn babies

\begin{tabular}{|c|c|c|c|}
\hline \multicolumn{2}{|l|}{ Mothers } & \multicolumn{2}{|c|}{ Baby (cord blood) } \\
\hline Range & $n=79(\%)$ & Range & $n=81(\%)$ \\
\hline \multicolumn{4}{|c|}{ Vitamin D (ng/ml) } \\
\hline$<20$ & $64(81)$ & $<20$ & $29(35.8)$ \\
\hline $20-29$ & $9(11.4)$ & $20-29$ & $30(37)$ \\
\hline 30-100 & $6(7.6)$ & $30-100$ & $22(27.2)$ \\
\hline$>100$ & $0(0)$ & $>100$ & $0(0)$ \\
\hline \multicolumn{4}{|l|}{ Calcium (mg/dl) } \\
\hline$<8.4$ & $53(67)$ & $<9$ & $52(64.2)$ \\
\hline $8.4-\quad 10.2$ & $26(33)$ & $9-11.5$ & $29(35.8)$ \\
\hline$>10.2$ & $0(0)$ & $>11.5$ & $0(0)$ \\
\hline
\end{tabular}




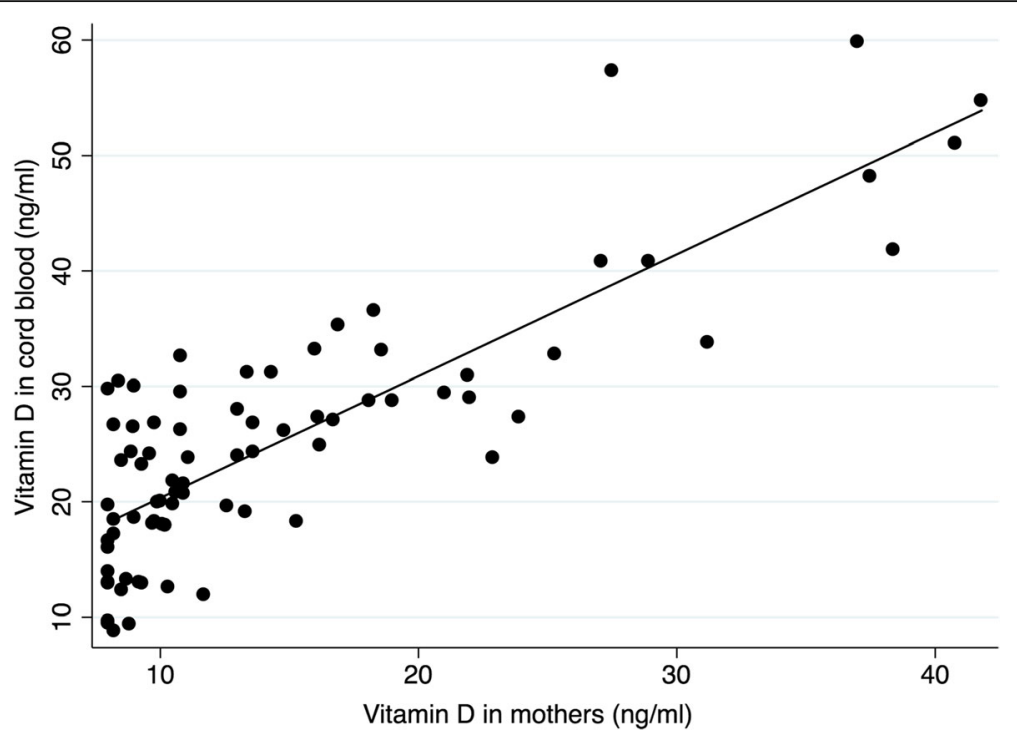

Fig. 2 Linear relationship between serum vitamin D in mother and cord blood (newborn)

vitamin $\mathrm{D}$ levels as compared to the calcium levels (adjusted coefficient of linear regression was 1.04 versus 0.53 ).

The study has some limitations. The study site was a non-governmental hospital; the services were not free of cost as that of governmental hospital, so the study population tended to be pregnant women of middle or higher socio-economic status. Due to this, the prevalence of vitamin $\mathrm{D}$ deficiency could have been underestimated. As the study was carried over only for 6 months the effects of seasonal variations could not be studied.

\section{Conclusion}

We have found a high prevalence of vitamin D deficiency among the pregnant women and their newborn babies in Nepal. Further large studies are needed to explore the possible causes of vitamin D deficiency. Regular adequate supplementation of vitamin D and calcium are needed during pregnancy.

\section{Abbreviations \\ 25(OH)D2/D3: 25 - Hydroxyvitamin D2/D3; AAP: American Academy of Pediatrics; ACOG: American College of Obstetrics and Gynecologists; \\ CDC: Center for Disease Control; NHRC: Nepal Health Research Council; o-CPC: o-Cresolphthalein Complexone; RCOG: Royal College of Obstetricians and Gynecologists; SD: Standard Deviation}

\section{Acknowledgements}

We would like to thank all the pregnant women and babies who participated in this study. We are grateful to Mr. Shyam Sundar Dhaubhadel, Founder of Siddhi Memorial Foundation for his kind support during this research, and all the nursing staff and doctors in the hospital who helped to complete this study.

\section{Funding}

The study was funded by Nepal Paediatric Society (NEPAS), Kathmandu, Nepal. NEPAS did not have any role in the study design, and the collection, analysis and interpretation of the data in this study.

\section{Availability of data and materials}

De-identified data and related material of this study are available upon reasonable request from the corresponding author.

\section{Authors' contributions}

DS and BGD conceptualized the study. All the authors contributed in designing the study, revising the proposal and approved the study. DS designed the questionnaire, analyzed the data, and prepared the first draft of the manuscript. SB and SP took the consent and collected the data. RKS entered the data in Epi Info and helped in data analysis. GBR, $\mathrm{RS}$, RP helped to collect the data and prepare the manuscript. CS and BGD helped to analyze the data, and edit the manuscript, AKS collected the blood samples and conducted the laboratory tests. All the authors approved the final version of the manuscript.

Ethics approval and consent to participate

Ethical approval was obtained from Nepal Health Research Council (NHRC) to conduct this research. All the eligible pregnant women were approached and a written informed consent was obtained before enrolling them in the study.

\section{Consent for publication}

Not applicable

\section{Competing interests}

The authors declare that they have no competing interests.

\section{Publisher's Note}

Springer Nature remains neutral with regard to jurisdictional claims in published maps and institutional affiliations.

\section{Author details}

'Department of Paediatrics, Siddhi Memorial Hospital, Bhaktapur, Nepal.

${ }^{2}$ School of Tropical Medicine and Global Health (TMGH), Nagasaki University, Nagasaki, Japan.

Received: 30 October 2018 Accepted: 2 May 2019

Published online: 29 May 2019

\section{References}

1. Bhalala U, Desai M, Parekh P, Mokal R, Chheda B. Subclinical Hypovitaminosis D among exclusively breastfed young infants. Indian Paediatrics; 2007. p. 44.

2. RCOG. Vitamin D in Pregnancy. Scientific Impact Paper 2014;43. https:// www.rcog.org.uk/globalassets/documents/guidelines/scientific-impactpapers/vitamin_d_sip43_june14.pdf. Assessed 01 Jun 2018. 
3. Harris A. Vitamin D deficiency in Pregnant Women at a tertiary Hospital in Western Sydney. Obstet Gynecol Int J. 2017. https://doi.org/10.15406/ogij. 2017.07.00234

4. Abbasian M, Chaman R, Amiri M, Ajami ME, Jafari-Koshki T, Rohani H, Taghavi-Shahri SM, Sadeghi E, Raei M. Vitamin D deficiency in Pregnant Women and their neonates. Glob J Health Sci. 2016:8:54008.

5. Ayadi ID, Nouaili EB, Talbi E, Ghdemssi A, Rached C, Bahlous A, Gammoudi A, Hamouda SB, Bouguerra B, Bouzid K, et al. Prevalence of vitamin D deficiency in mothers and their newborns in a Tunisian population. Int J Gynaecol Obstet. 2016:133:192-5.

6. Bowyer L, Catling-Paull C, Diamond T, Homer C, Davis G, Craig ME. Vitamin D, PTH and calcium levels in pregnant women and their neonates. Clin Endocrinol. 2009:70:372-7.

7. Hollis BW, Wagner CL. Assessment of dietary vitamin D requirements during pregnancy and lactation. Am J Clin Nutr. 2004;79:717-26.

8. Zeghoud F, Vervel C, Guillozo H, Walrant-Debray O, Boutignon H, Garabedian M. Subclinical vitamin D deficiency in neonates: definition and response to vitamin D supplements. Am J Clin Nutr. 1997;65(3):771-8.

9. Greer FR. Vitamin D deficiency —it's more than rickets. J Pediatr. 2003;143(4); 422-3.

10. Masood SH, labal MP. Prevalence of Vitamin D deficiency in South Asia. Pak J Med Sci. 2008;24(6):891-7.

11. Raina K, Verma HN, Bhatia AS. Prevalence of Vitamin D deficiency in Jammu region. J K Science. 2014;16:21-3.

12. Sachan A, Gupta R, Das V, Agarwal A, Awasthi PK, Bhatia V. High prevalence of vitamin $D$ deficiency among pregnant women and their newborns in northern India. Am J Clin Nutr. 2005;81:1060-4.

13. Malhotra N, Mithal A. Vitamin D status in Asia. International Osteoporosis Foundation. 2009. https://www.iofbonehealth.org/sites/default/files/PDFs/ Vitamin_D_Asia.pdf. Accessed 1 Jun 2018.

14. Shah P, Kulkarni S, Narayani S, Sureka D, Dutta S, Vipat AS, et al. Prevalence study of Vitamin D deficiency and to evaluate the efficacy of Vitamin D3 granules 60,000 IU supplementation in Vitamin D deficient apparently healthy adults. Indian J Clin Practice. 2013;23(12):827-32.

15. Ulak M, Chandyo RK, Thorne-Lyman AL, Henjum S, Ueland PM, Midttun O, et al. Vitamin status among breastfed infants in Bhaktapur. Nepal Nutrients. 2016;8(3):149.

16. Shrestha S, Shrestha L, Jha DK. Vitamin D status among individuals attended in health home care Centre, Lalitpur, Nepal. Nepal Med Coll J. 2012;14(2):84-7.

17. Haugen J, Ulak M, Chandyo RK, Henjum S, Thorne-Lyman AL, Ueland PM, et al. Low prevalence of Vitamin D insufficiency among Nepalese infants despite high prevalence of Vitamin D insufficiency among their mothers. Nutrients. 2016;8(12).

18. Edwards $\mathrm{MH}$, Cole ZA, Harvey NC, Cooper C. Global epidemiology of Vitamin D status. The Journal of Aging Research and Clinical Practice. 2014;3(3):148-58.

19. Aghajafari F, Nagulesapillai T, Ronksley PE, Tough SC, O'Beirne M, Rabi DM Association between maternal serum 25-hydroxyvitamin D level and pregnancy and neonatal outcomes: systematic review and meta-analysis of observational studies. BMJ. 2013;346:f1169.

20. Scholl TO, Chen X. Vitamin D intake during pregnancy: association with maternal characteristics and infant birth weight. Early Hum Dev. 2009;85: $231-4$.

21. Sahu M, Bhatia V, Aggarwal A, Rawat V, Saxena P, Pandey A, et al. Vitamin D deficiency in rural girls and pregnant women despite abundant sunshine in northern India. Clin Endocrinol. 2009;70:680-4.

22. Wegienka G, Kaur H, Sangha R, Cassidy-Bushrow AE. Maternal-cord blood Vitamin D correlations vary by maternal levels. J Pregnancy. 2016;2016: 7474192.

23. Yu CK, Sykes L, Sethi M, Teoh TG, Robinson S. Vitamin D deficiency and supplementation during pregnancy. Clin Endocrinol. 2009;70:685-90.

24. WHO. Vitamin D Supplementation in Pregnant Women. 2012. http:// apps.who.int/iris/bitstream/handle/10665/85313/9789241504935_eng.pdf. Accessed 1 Jun 2018

25. Maternal health division government of India. National Guidelines for calcium Supplementation during pregnancy and lactation. 2014. http:// www.nrhmhp.gov.in/sites/default/files/files/NG_calcium.pdf. Accessed 1 June 2018.

26. WHO. Guideline: Calcium supplementation in pregnant women. 2013. http://apps.who.int/iris/bitstream/handle/10665/85120/9789241505376 eng.pdf. Accessed 1 Jun 2018.
27. Grant CC, Stewart AW, Scragg R, Milne T, Rowden J, Ekeroma A, et al. Vitamin D during pregnancy and infancy and infant serum 25-hydroxyvitamin D concentration. Pediatrics. 2014;133(1):e143-53.

28. ACOG Committee on Obstetric Practice. ACOG Committee opinion no. 495: Vitamin D: screening and supplementation during pregnancy. Obstet Gynecol. 2011;118(1):197-8.

29. Holick MF, Binkley NC, Bischoff-Ferrari HA, Gordon CM, Hanley DA, Heaney $R P$, et al. Evaluation, treatment, and prevention of vitamin D deficiency: an Endocrine Society clinical practice guideline. J Clin Endocrinol Metab. 2011; 96:1911-30
Ready to submit your research? Choose BMC and benefit from:

- fast, convenient online submission

- thorough peer review by experienced researchers in your field

- rapid publication on acceptance

- support for research data, including large and complex data types

- gold Open Access which fosters wider collaboration and increased citations

- maximum visibility for your research: over $100 \mathrm{M}$ website views per year

At BMC, research is always in progress.

Learn more biomedcentral.com/submissions 